\title{
DAS NOTAS DE LEITURA À TESE: ALGUNS APONTAMENTOS SOBRE A ELABORAÇÃO DE EDUCAÇÃO E ATUALIDADE BRASILEIRA, DE PAULO FREIRE
}

\author{
FROM THE READING NOTES TO THE THESIS: SOME \\ NOTES ON THE ELABORATION OF EDUCAÇÃO E \\ ATUALIDADE BRASILEIRA, BY PAULO FREIRE
}

\author{
Sérgio C. Fonseca* \\ Fernanda Ribeiro Ruffo Roberto*
}

\begin{abstract}
RESUMO: No conjunto dos estudos sobre Paulo Freire e sua obra, sua tese Educação $e$ atualidade brasileira mereceu atenção de pesquisas, como as de Vanilda Paiva e Celso Beisiegel, que nos anos 1970 apontaram os constituintes teóricos e metodológicos, bem como as circunstâncias históricas e as questões conjunturais que repercutiram na escrita da tese. Outros trabalhos mais recentes, a exemplo de Maria Cecília Teixeira, José Eustáquio Romão e Ana Inês Souza, também se ocuparam com esse texto, que é um dos primeiros de Paulo Freire e de uma fase que precede seu exílio forçado em 1964. Portanto, no conjunto da obra freireana, mesmo sendo um texto de início de trajetória e tendo encorpado o conteúdo de outro livro mais conhecido, Educação como prática da liberdade, a tese de Freire ainda tem algo a revelar, como é caso da proposta do presente artigo. Por essa razão, colocamos em destaque, neste artigo, alguns aspectos da elaboração de Educação e atualidade brasileira a partir do registro do processo de estudo de Freire deixado em anotações nos livros que constam da bibliografia dessa tese.
\end{abstract}

Palavras-chave: Paulo Freire; Educação e atualidade brasileira; Democracia.

ABSTRACT: Among the studies on Paulo Freire and his work, his thesis Educação e atualidade brasileira deserved attention from studies, such as those of Vanilda Paiva and Celso Beisiegel who, at 1970's, pointed out the theoretical and methodological constituents, as well as the historical circumstances and conjuncture issues that had an effect on the writing of this thesis. More recently, some works have also explored this text, which is one of Paulo Freire's first publications in a phase that precedes his forced exile in 1964. Therefore, in light of the whole of Freirean work, even being a text from the beginning of his trajectory and having full-bodied the content of another better known book, Educação como prática da liberdade, Freire's thesis still has something to

\footnotetext{
* Doutorado em educação pela Universidade Estadual Paulista "Júlio de Mesquita Filho" (Unesp) e livre docência pela Universidade de São Paulo (USP), com estágio de pósdoutorado pela Universidade Federal de Minas Gerais (UFMG). Professor associado da USP e coordenador do Laboratório de Estudos e Pesquisas sobre Infância, Juventude e Educação da USP. Contato: sergiofonseca@usp.br

* Psicóloga e mestranda em educação pela Universidade de São Paulo (USP). Contato: fernandaribeirorufforoberto@gmail.com
} 
reveal, as this article proposes to demonstrate. For this reason, we highlight some aspects of the process of elaboration of Educação e atualidade brasileira, from the record of Freire's study process that was left in notes in the books that appear in the bibliography of his thesis.

Keywords: Paulo Freire; Educação e atualidade brasileira; Democracy.

\section{INTRODUÇÃO}

À medida que Paulo Freire ganhou notoriedade em razão da repercussão dos trabalhos de educação de adultos e da elaboração do método de alfabetização neles aplicado, sua obra e suas realizações tornaram-se objeto de estudo e debate já nos anos 1960. Desde as primeiras aplicações no Recife, o método recebeu a atenção de Pierre Furter, que foi a campo com o propósito de estudar as experiências que naquele momento eram inovadoras em termos de educação de adultos (GADOTTI, 1996; FREIRE, 2017). Nesse mesmo período, Celso Beisiegel, atuando no Centro Regional de Pesquisas Educacionais, em São Paulo, iniciou investigações pioneiras sobre o método de alfabetização e as experiências onde fora testado com sucesso (primeiro acompanhando movimentos de educação popular na Grande São Paulo e, a seguir, na área precursora no interior do Rio Grande do Norte) e que, mais tarde, no final dos anos 1970, resultariam em um trabalho acadêmico, publicado em meados da década seguinte (BEISIEGEL, 1982). Ainda nos anos 1970, Vanilda Pereira Paiva (1980) examinou uma das matrizes teóricas da tese de Paulo Freire, apontando a forte influência do nacionaldesenvolvimentismo em Educação e atualidade brasileira. Em comum, Paiva e Beisiegel reconhecem outras duas matrizes formadoras de Paulo Freire enquanto jovem intelectual engajado em fins dos anos 1950: o escolanovismo e o existencialismo cristão.

Os estudos dessa geração precursora são uma amostra da fortuna crítica acumulada precocemente por Paulo Freire em razão de sua extensa obra. Em meados da década de 1990, o livro organizado por Moacir Gadotti (1996) - Paulo Freire: uma bibliografia - atestou, por meio de várias páginas de listagem bibliográfica, que até aquela quadra o estudo, a divulgação, o debate 
e a crítica - entre variadas motivações - resultaram em numerosa produção na forma de artigos, teses, dissertações e livros sobre a obra freireana. Walter Kohan (2019) aponta que Freire teve alterações quanto às influências em geral recebidas da filosofia europeia e que esses núcleos de referência se alteraram em razão de momentos de mudança em sua trajetória. Em trabalho anterior (FONSECA, 2011) sustentamos que entre os anos de 1940 e 1970 há três ciclos importantes na trajetória de Freire e que indicam, primeiro, sua adesão a um projeto de país em parte ancorado no programa escolanovista e de outra parte no desenvolvimentismo, sucedido por um segundo, marcado pelo golpe de estado de 1964, pela prisão, exílio, e pela troca de pele já explícita com a publicação de Educação como prática da liberdade. O terceiro ciclo seria a assunção de posições teóricas e políticas de fundo revolucionário, sem explicitar a adesão a uma determinada teoria da revolução, porém definidas por uma opção pela mudança radical das condições sociais tal como expressa o teor de Pedagogia do oprimido.

Recentemente, pouco antes do cinquentenário da publicação da Pedagogia do oprimido (uma das obras de Freire mais reconhecidas no cenário mundial), o alcance de seus trabalhos foi atualizado, vez que, em 2016, o levantamento realizado por Elliot Green (2016) colocou esse livro do educador pernambucano como o terceiro mais citado globalmente no campo de ciências sociais. A considerar somente essas duas evidências o estudo de Paulo Freire poderia seguramente justificar um ou mais trabalhos no estilo estado da arte. A densidade de seu pensamento educacional, por exemplo, deu causa à produção de um dicionário (STRECK; REDIN; ZITKOSKI, 2010) com mais de duas centenas de verbetes com termos e expressões do universo freireano. Nessa perspectiva, a obra freireana segue como objeto de estudo em termos nacionais e internacionais, dando margem a numerosa produção de análises de suas ideias, da sua trajetória e de suas contribuições para a educação.

Por essa razão, a tarefa de propor mais um estudo sobre Paulo Freire parece sempre custosa, provavelmente reiterativa ou, no limite, devedora de um levantamento bibliográfico extenso. No caso ora tratado no presente artigo, partiremos de questões outrora discutidas por Beisiegel (1982), 
Paiva (1980), Gerhardt (1996), Teixeira (2000), Romão (2001) Souza et alii (2001), a fim de colocar em primeiro plano um ponto até agora marginal: o registro de alguns procedimentos de estudo de Paulo Freire aplicados à elaboração de sua tese. Para a consecução desse propósito tomamos como fontes as anotações de Paulo Freire nos livros de sua primeira biblioteca, com destaque para os títulos que possuem notas, fichamentos e resenhas em suas páginas e que constam na bibliografia de Educação e atualidade brasileira. Apresentaremos algumas transcrições dessas marginalias de Freire nos livros de sua biblioteca pessoal e cotejaremos com passagens de Educação e atualidade brasileira que apresentam estreita correspondência com o sentido e os temas "fichados" por ele e partes de sua tese para efeito de comparação desses dois materiais. Quanto à transcrição das marginalias procuramos preservar a forma como Freire as elaborou, ora reproduzindo o trecho do texto do livro com seus grifos, por sua vez, seguidos por suas notas e comentários.

\section{A DEMOCRACIA COMO PONTO CENTRAL DA TESE DE PAULO FREIRE}

Os textos freireanos pré-1964 sugerem ter a característica de ensaios ou, nessa mesma direção, de exercícios de elaboração intelectual que teriam sido, possivelmente, superados por obras de maior envergadura, como parece ser o caso de Educação como prática da liberdade que, em nome da produção de um livro que sintetizasse o método de alfabetização de adultos, que refletisse sobre a experiência política que levou à ruptura provocada pelo Golpe e que apresentasse os contornos de uma teoria do conhecimento, absorveu o conteúdo de escritos anteriores.

É certo que ocorreu a transposição de parte do texto de Educação e atualidade brasileira para Educação como prática da liberdade, como também é factível que esse segundo livro introduziu questões pouco ou nada vislumbradas no texto de 1959. Até Educação e atualidade brasileira a opção por uma agenda de reformas desenvolvimentistas, pela ampliação do espaço de participação popular dentro da democracia representativa e por um profundo processo de mudança da educação escolar pública (nos moldes propostos por 
Anísio Teixeira) eram temas fortes para os quais Paulo Freire estruturou uma série de reflexões de fundo (e profundas) a fim de mostrar que a conjuntura do pós-Segunda Guerra Mundial era uma fase de trânsito, de mudanças, de contradições entre permanências e o novo que apontava no horizonte. Por isso, a questão da democracia, embora se apresente no texto desse livro compatível com a moldura da forma representativa, não se resume a votar e aos processos eleitorais, porquanto a consciência dos indivíduos e a formação de ligações entre as pessoas que fossem capazes de produzir o reconhecimento da forma coletiva de vida, na qual as decisões são construídas em processos dialogados, compartilhados, com espaço para a contradição, para a deliberação, são assuntos postos para a educação. Antes de tudo, o problema era o modo de vida democrático e a consciência dos indivíduos educada para viver a democracia.

Para enfrentar uma questão dessa natureza, Paulo Freire escolheu demonstrar que a história da formação brasileira não habilitara o homem nacional (expressão usada à larga em Educação e atualidade brasileira) para o viver democrático. O peso do passado e um presente de mudanças formavam um campo de tensão que leva o nome de antinomia fundamental da atualidade na tese de Freire, expressa pela oposição entre a "inexperiência democrática" frente a "emersão do povo na vida pública nacional". A industrialização no Brasil havia provocado a emersão do povo na vida pública nacional, mas, ainda faltava a elaboração de uma consciência média (na forma transitivo crítica).

O teor do texto da tese doutoral de Freire, a começar pelo título, não deixa dúvidas a respeito da opção pela alternativa das reformas da escola e da educação brasileira numa fase de trânsito. Sob esse ponto de vista, aparentemente o problema da democracia estaria ofuscado ou subordinado às reformas da educação escolar. Entretanto, três pontos são determinantes para o fato de a ampliação da participação popular na esfera política (ou, como Freire explica, a emersão do povo na vida pública nacional), ser a questão central em Educação e atualidade brasileira e, tão logo, a democracia represente a resposta a esse problema: a) o primeiro ponto diz respeito ao peso da história, ou seja, da formação brasileira enquanto não superação das 
raízes coloniais: b) a outra dimensão do peso da história é a atualidade, o que seria o segundo ponto, pois a conjuntura de meados do século $X X$ equivaleria a um tempo de contradições, de ímpetos participativos, mas, limitados; de industrialização, enquanto forma de produção moderna, cujos efeitos incidiam sobre as condições sociais e culturais brasileiras e que estava por requerer o devido programa de reformas que orientasse esse processo, que amplificasse o alcance da participação popular na esfera política; c) o terceiro ponto é a inorganicidade da educação brasileira frente às exigências do desenvolvimento econômico e da emersão do povo na vida pública nacional.

\section{NA PRIMEIRA BIBLIOTECA DE PAULO FREIRE ESTÃO AS PISTAS SOBRE A ELABORAÇÃO DO TEXTO DE EDUCAÇÃO E ATUALIADE BRASILEIRA}

Até que Paulo Freire chegasse a publicar alguns de seus livros mais reconhecidos, como Educação como prática da liberdade, Pedagogia do oprimido e Extensão ou comunicação, há outros textos escritos e vindos a lume antes desses num período entre 1958 e 1963. A sua tese de doutoramento, por exemplo, apresentada em 1959, ganhou nova edição somente em 2001 (ROMÃO, 2001). Com essa tese, Paulo Freire prestou o concurso para cátedra de História e Filosofia da Educação na Universidade do Recife, em 1959. Antes dessa tese, ele publicou alguns artigos no Diário do Recife entre março e abril de 1957, dois artigos na Revista Brasileira de Estudos Pedagógicos, em 1958 e 1961 e, mais tarde, em 1963 o livro Alfabetização e conscientização (GADOTTI, 1996; FREIRE, 2017). Parte substancial do texto de Educação como prática da liberdade foi retirada de Educação e atualidade brasileira que, por volta de 1967, estava no limbo, praticamente arquivada em razão da cassação de seus direitos políticos pela ditadura civil-militar, no poder desde 1964 (ROMÃO, 2001; FREIRE, 2017; HADDAD, 2019). Outra parte dos conceitos presentes no conteúdo de Educação como prática liberdade foi ensaiada no artigo, de 1961, Conscientização e alfabetização: uma nova visão do processo, publicado na Revista de Cultura da Universidade do Recife. Além de artigos e livros, antes de 1964, temos também relatórios, manuais para os 
Círculos de Cultura e documentos de circulação circunscrita, assinados por Freire (GADOTTI, 1996).

Em parte devido a uma finalidade prática, Paulo Freire passou dos escritos curtos (artigos), da autoria de documentos institucionais (relatórios dos trabalhos no SESI) e de textos de formação (para orientar os trabalhos dos Círculos de Pais e Professores) para uma produção de maior fôlego a partir de sua tese apresentada para um concurso. Tal passagem ocorre na segunda metade da década de 1950, justamente quando Freire ampliava seu campo de atuação na educação ao colaborar com ações educativas em movimentos sociais, em cursos escolares alternativos, assim como iniciava a docência na universidade, entre outras ocupações (FREIRE, 2017). A conjugação da ação e da prática desde esse período de juventude intelectual e militante é frequentemente reconhecida por estudiosos de variados posicionamentos teóricos (BEISIEGEL, 1982; HADDAD, 2019; KOHAN, 2019) como características que formaram Paulo Freire e que forneceram o material de seus textos.

Por outro lado, um aspecto do processo criativo das ideias e conceitos expressos em seus textos desse período permanece periférico nos estudos sobre a obra freireana, especialmente sobre seus trabalhos do período antecedente ao exílio, portanto, pré-1964. Antes de tudo, Paulo Freire elaborou seus processos de estudo baseados numa plataforma, sua biblioteca pessoal, e num procedimento de registro - à primeira vista comum a qualquer estudante - na forma de notas, ou, marginalias, cujo propósito visava a dar forma aos primeiros insights durante o processo de leitura. De acordo Ana Maria Araújo Freire (2017), esse era um procedimento mental cotidiano, pois acontecia com frequência, segundo seu relato, ver Freire anotar em pedaços de papel, fichas, ou "no cantinho da cabeça" as suas ideias, na medida em que elas surgiam na rua, nas conversas, nas leituras ou em alguma conferência ou entrevista que ele participava. Para Ana Maria Araújo Freire, esse hábito do educador pernambucano está muito atrelado a sua forma de encarar a leitura (do mundo) e a escrita de forma extremamente integrada. Esses dois atos só poderiam ser entendidos como uma unidade para Paulo Freire, vez que quando "ele 'escrevia', ia 'lendo' outros autores e relendo a si próprio da mesma maneira 
que ao ler a si e aos outros ia escrevendo e reescrevendo sua nova leitura do mundo" porque "há no ato de ler e no ato de escrever uma intrínseca relação dialética que torna impossível dissociarmos um do outro" (FREIRE, 2017, p. 315).

Considerando a integridade do ler/escrever como um valor para Paulo Freire, as suas escritas informais são indícios relevantes para entender sua visão de mundo. Visão de mundo explicitada pelas suas obras publicadas, nos manuscritos preparatórios aos livros (como é o caso do manuscrito de Pedagogia do oprimido) e também pelas escritas de trechos de próprio punho encontrados em obras que ele estudou. Em outras palavras, uma parte do processo de elaboração das ideias de Paulo Freire pode ser refeita a partir de duas espécies de registros, sendo um deles os exemplares restantes da biblioteca que ele reuniu até 1964 e, o outro, as anotações feitas por ele no interior de vários exemplares que, por várias vezes, acabaram transpostas ou, se não, parafraseadas na sua tese, Educação e atualidade brasileira. Se o mero fato de reunir livros ao longo de anos de sua vida não é suficiente para desvendar o processo de estudo de Freire, as anotações no interior de diversos exemplares oferecerem pistas úteis ao fim de reconstituir fragmentos do processo de preparação do texto que, primeiro, teve um fim prático - disputar um concurso - e depois foi incorporado a um livro que abriu um ciclo de obras de sua autoria de grande reconhecimento e influência.

Dos primeiros livros reunidos por Freire restaram alguns exemplares que compõem parte do acervo formado por sua primeira biblioteca pessoal, atualmente mantida pelo Instituto Paulo Freire. Em vários desses volumes é possível encontrar anotações de próprio punho de Paulo Freire que registram sua interação com o texto lido, o destaque atribuído a temas recortados da leitura e a seleção de passagens que, cotejadas com os escritos do período pré-1964, são comparáveis a fragmentos que foram aplicados na montagem de seus livros e artigos. Ao examinarmos mais amiúde esse processo de estudo de Freire percebemos algumas variações de acordo com as seguintes formas: a) grifo/destaque de passagens do texto lido: procedimento no qual linhas são sublinhas e, por vezes, algum termo é anotado na margem; b) anotações com 
séries de ideias e temas nas margens ou nos pés de página: é um tipo de nota qual Freire organiza listas de destaques da leitura e a página na qual estão localizados; c) micro resenhas nas páginas avulsas e em branco ao final de determinados volumes: essa representa a forma de escrita que mais se aproxima de um rascunho do texto final de Educação e atualidade brasileira, na qual Freire passa da coleção de itens em destaque ao texto contínuo, cujo conteúdo apresenta seus argumentos, raciocínios e análises que aparecem em sua tese; d) apontamentos sobre quais temas destacar a partir do texto lido e que indicam sua eventual inserção na tese: algumas notas são composta por listas de pontos a serem mais aprofundados e que, eventualmente, são aprofundados em sua tese. Não raro, as anotações conjugam esses procedimentos de registro em uma mesma página, com o uso associado de destaques de linhas sublinhadas, termos anotados na margem, notas de pé de página e, menos ocorrentes, micro resenhas.

As marginalias e as pequenas resenhas nas páginas sobressalentes dos volumes mostram igualmente certas relações que ele fazia com outras leituras anteriores ou simultâneas e também com situações destacadas de suas experiências enquanto educador, como nesta nota escrita no livro de Gabriel Marcel, Los hombres contra lo humano, após grifar uma passagem e, no pé da página, remeter a outras duas leituras:

[Passagem assinalada no livro] "Admitiendo que la propaganda no pueda ser clasificada, de primera intención, entre las técnicas de envilecimiento, cabe reconocer que entre éstas y aquélla existe un íntimo parentesco; para ello será ademas necesario formarse de la propaganda una idea bien clara."

[Anotação de Paulo Freire no livro] Ver a propósito da propaganda - Mannheim - Diagnostico de nuestro tiempo Aldous Huxley - El fin y los medios -.

A nota faz menção a outros dois livros, Diagnóstico de nuestro tempo, de Karl Mannheim, e El fin y los médios, de Aldous Huxley, que são citados em várias passagens de Educação e atualidade brasileira, bem como são referenciais, especialmente o primeiro, para entender a atualidade como uma fase de trânsito, de mudanças, de ascensão das sociedades industriais, 
de época de aprendizado da democracia (no mundo e, particularmente, no Brasil) e que, enquanto formação social e mental moderna, demandam compreender que, apesar do progresso provocado pela industrialização, existe o perigo da formação de consciências fanatizadas, o que é uma aproximação entre Marcel e Mannheim elaborada por Paulo Freire na posição de leitor de ambos. Essa produção de convergência segue nas anotações de Freire na página 42 de Los hombres contra lo humano, de Gabriel Marcel:

[Passagens assinaladas no livro] "El servidor es lo contrario del esclavo. Pero la logomaquia contemporánea confunde estos dos términos".

"Correspondería pensar que es solamente en el seno de grupos muy limitados, de muy pequeñas comunidades que la libertad al servicio de la gracia puede ser efectivamente ejercida."

"O criti-massivismo - grupos primários [anotação de Paulo Freire] "no simplemente el tejido nacional. Pues es necesario, pienso, ver mucho más lejos que la nácion".

[Anotação de Paulo Freire no livro] Posição idêntica a esta, do ponto de vista, porém, exclusivamente sociológico, é defendida por Mannheim - Diagnostico de nuestro tiempo.

Considerando que vários volumes da primeira biblioteca de Paulo Freire apresentam essas notas no interior das páginas, preferimos mapear quais obras contém esses registros de leitura e entre essas quais foram citadas em sua tese doutoral. No levantamento encontramos 84 obras (de diversos autores) com anotações de Freire e que foram disponibilizadas para consultas através da rede mundial de computadores pelo Instituto Paulo Freire. Desses $84 \mathrm{com}$ anotações, pelo menos 40 títulos fazem parte das obras citadas em alguns de seus artigos, bem como em sua tese ou somente arroladas na bibliografia desse trabalho. Por sua vez, entre esses 84 volumes, temos textos em diferentes línguas de autores de diferentes nacionalidades, conforme 0 presente quadro: 


\section{Quadro 1: Nacionalidade das autoras e autores dos livros da biblioteca de Paulo Freire}

\begin{tabular}{|c|c|}
\hline Nacionalidade da(o) autora(or) & Quantidade de exemplares \\
\hline alemã & 3 \\
\hline americana & 2 \\
\hline argentina & 1 \\
\hline austríaca & 2 \\
\hline belga & 37 \\
\hline brasileira & 1 \\
\hline espanhola & 7 \\
\hline francesa & 1 \\
\hline guatemalteca & 4 \\
\hline húngara & 8 \\
\hline inglesa & 2 \\
\hline italiana & 7 \\
\hline não identificada & 2 \\
\hline portuguesa & 1 \\
\hline romena & 1 \\
\hline suíça & $\mathbf{8 4}$ \\
\hline Total & \\
\hline & \\
\hline & 2 \\
\hline
\end{tabular}

Do conjunto de mais de oitenta títulos com notas de leitura registradas por Freire nas margens de páginas ou nas páginas em branco de fim dos livros, como apontamos, localizamos 10 dessas obras textualmente citadas ou mencionadas em Educação e atualidade brasileira. O quadro a seguir lista quais obras tem anotações e quais são citadas na tese de Freire:

\section{Quadro 2: obras com anotações de Paulo Freire citadas em Educação e atualidade brasilieira}

\begin{tabular}{|c|c|}
\hline Autor & Livro \\
\hline Aldous Huxley & El fin y los medios \\
\hline Caio Prado Júnior & História econômica do Brasil \\
\hline Caio Prado Júnior & Evolução política do Brasil e outros estudos \\
\hline Fernando Azevedo & A cultura brasileira (tomo três) \\
\hline Fernando Azevedo & A cultura brasileira (tomo um) \\
\hline Gabriel Marcel & Los hombres contra lo humano \\
\hline Juan Mantovani & Educacion y plenitud humana \\
\hline Karl Mannheim & El hombre y la sociedade en la época de crisis \\
\hline Peter Drucker & La nueva sociedad \\
\hline Simone Weil & Raíces del existir \\
\hline
\end{tabular}


Com efeito, essa é uma amostra do arco de referências presente no texto de Educação e atualidade brasileira. Na tese de Freire temos 57 obras citadas no corpo do texto e mais 28 obras não citadas diretamente, mas, listadas na bibliografia. Dessas 85 referências, 26 são de autores brasileiros e as demais de estrangeiros.

Esse repertório de referências organizado por Freire em sua tese está concentrado em alguns núcleos cartesianamente concatenados e ensejados pela apresentação do problema da antinomia fundamental da atualidade, por sua vez, completada por três capítulos que tematizam sobre corolários dessa questão central. Desse modo, as contradições resultantes da emersão do povo na vida pública nacional definem a discussão do primeiro capítulo, seguida pelo problema da ausência histórica de experiências de participação do homem nacional na vida pública, tema do segundo capítulo e, por fim, a questão da revisão do agir educativo e da escola no terceiro capítulo. Para cada um desses capítulos encontramos certos núcleos de referências, algumas citadas somente num único capítulo e outras transversais, mencionadas em várias partes da tese. Entre os autores brasileiros podemos delinear alguns núcleos expressivos da produção intelectual nacional da primeira metade do século XX:

a) nacional desenvolvimentismo: representado na tese de Freire por nomes ligados ao Instituto Superior de Estudos Brasileiros (ISEB), como Alberto Guerreiro Ramos, Roland Corbusier, Hélio Jaguaribe, Nelson Werneck Sodré e Álvaro Vieira Pinto;

b) escolanovismo brasileiro do Manifesto de 1932 reativado nos anos 1950: representado na tese por obras de Anísio Teixeira e Fernando de Azevedo, embora o segundo seja mais requerido por Freire como intérprete do Brasil que propriamente enquanto um escolanovista de cepa;

c) formuladores de interpretações historiográficas e sociológicas sobre a formação do Brasil: núcleo este constituído por nomes reconhecidos por posições teóricas e políticas dispares entre si, mas, reunidos por Freire 
com o objetivo de elucidar as condições de formação do Brasil numa perspectiva totalizante, considerando o peso da cultura, da economia e das relações sociais na mentalidade do homem nacional e das estruturas de poder refratárias à participação e que deram em formas de vida pública fechadas e nada democráticas. Nesse núcleo temos Caio Prado Júnior, Sérgio Buarque de Holanda, Gilberto Freyre e Oliveira Vianna, todos reunidos por Freire no intuito de formar um repertório de explicadores da formação do Brasil composto por diferentes expressões teóricas que vão dos marxistas aos expoentes de posições intelectuais opostas, se não conservadoras, caso de Caio Prado Júnior de uma parte e Oliveira Vianna, de outra. Nesse núcleo também estão incluídos nomes estrangeiros reconhecidos pelos relatos de visitas e passagens pelo Brasil como John Luccock, Rugendas e Saint-Hilaire;

d) analistas sociológicos e políticos da atualidade brasileira: esse não é um núcleo homogêneo por completo como as referências escolanovistas e isebianas e também não está relacionado a um bloco temático coeso na tese, como no caso da revisão do passado amparada pela historiografia brasileira e a revisão do agir educativo e do sistema escolar orientada pela referência a Anísio Teixeira, por exemplo. Apesar dessa constatação, esse núcleo é o mais transversal da bibliografia nacional da tese porque tem como seu eixo a apropriação da sociologia de Alberto Guerreiro Ramos (responsável pelo setor de Sociologia do ISEB) e sua interpretação sobre a emergência da consciência crítica em razão das transformações na infraestrutura provocadas pela industrialização (BEISIEGEL, 1982). Desse núcleo de interpretação político sociológica da atualidade brasileira fazem parte como referências menores e até pontuais na tese Florestan Fernandes e Djacir Menezes e, de outra parte, Nelson Werneck Sodré que, tal qual Guerreiro Ramos, é um híbrido na tese, sendo apropriado por Freire a partir do pacote isebiano (projeto de país desenvolvimentista), mas encaixado na tese em razão de sua análise da formação das classes sociais.

Do núcleo dos explicadores do Brasil, um nome citável é o de Caio Prado Júnior, do qual temos duas obras que localizamos com marginalias 
escritas por Freire, Evolução política do Brasil, História econômica do Brasil e uma terceira citada na tese, Formação do Brasil contemporâneo. Ao colocar em perspectiva a formação do Brasil, começando pelo tipo de ocupação do território no período colonial, Freire destaca um problema de origem: o modelo da grande propriedade como vetor do povoamento. Nesse ponto, as notas de Freire nas páginas de História econômica do Brasil assinalavam o problema do tipo de povoamento:

O sentido comercial dos encontros dos encontros dos europeus com as novas terras - 15/16 - A ideia de povoamento só surge quando constatada a impossibilidade do acordo comercial numa vasta terra desabitada ou habitada por populações selvagens - 16 - O colono viria para as terras da América para dirigir a produção, só a contragosto como trabalhador - que outros trabalhassem para ele - 20 - Aqui chegados os colonos, criou-se entre nós, como forma de exploração agrária, a grande propriedade [ilegível] caracterizar todo o nosso [ilegível] de desenvolvimento. Dessa forma, a grande maioria dos colonos estabeleceu desde o início de sua chegada às nossas terras, suas relações com os senhores das propriedades à base da subordinação - 20/21 - O início da colonização efetiva do Brasil através de capitanias cujos donatários inauguraram o poder vertical - cabia-lhes a nomeação de autoridades administrativas, juízes, etc - 32/33 - A grande propriedade, a [ilegível] e o trabalho escravo - $34 \mid$ As bandeiras - caça ao índio - e a expressão territorial brasileira - 36 _ A experiência dos portugueses nos negócios da escravidão - o escravo negro substituto do índio - 36/37.

Por extensão, entre as marginalias que selecionamos essas notas registradas por Freire e ora transcritas contribuem para esclarecer como a tessitura dos argumentos (e o raciocínio) de Freire foi preparada desde o processo de leitura e registro dos insights até a redação de sua tese. Em Educação e atualidade brasileira o texto consta da seguinte forma:

Mas, mesmo assim, ao se criarem novas condições e surgirem as contingências que passariam a exigir dos descobridores mais do que simples feitorias comerciais e sim o povoamento, de que resultaria uma maior integração do homem com a terra, o que se observou foi a tendência ressaltada por Caio Prado, para procurarem os trópicos e neles se fixarem, somente aqueles que dispusessem de meios que os fizessem 
"empresário de um negócio rendoso; mas só a contragosto como trabalhador".

Ao lado disto e, possivelmente em parte por causa desta tendência, marchou a nossa colonização no sentido da grande propriedade. Da fazenda. Do engenho. Fazenda, engenho, terras grandes, imensas terras, doadas às léguas a uma pessoa só, que se apossava delas e dos homens que vinham povoá-las e trabalhá-las. (FREIRE, 1959, p. 66-7)

O tema da grande propriedade, do regime de capitanias e do desenho vertical das relações de poder, em que pese o fato de o livro de Caio Prado ser um tratado de história econômica, na forma de uma leitura de economia política da história brasileira, é definido por Freire no interesse de isolar um ponto da gênese do país com características de longa duração: desde o regime das capitanias o exercício do poder foi estabelecido de forma vertical, enquanto poder hierárquico, autoritário, anti-povo e senhorial. Freire considerava haver no Brasil de meados do século $X X$ processos não superados, de longa duração que, embora transmutados, se não atualizados, mantinham-se ativos e conflitantes com os progressos econômicos, culturais e sociais de uma sociedade em processo de industrialização. Na base dessa análise freireana, temos um debate entre a opção por uma sociedade agrária, dependente, ou por uma sociedade industrializada, economicamente altiva e democrática politicamente, entre "país velho e país novo", segundo Beisiegel (1982, p. 64). Por isso, a aproximação de Freire com dois projetos de país que apresentavam respostas para esse debate: o escolanovismo, do manifesto de 1932 e atualizado no novo manifesto de 1959, e o nacional desenvolvimentismo do ISEB. Ademais, a circunstância de Freire era Pernambuco, no coração do nordeste, região expressiva da economia e da sociedade agrárias. Celso Beisiegel (1982, p. 70), a este respeito, explica que a apropriação por Freire das interpretações sobre o Brasil de intelectuais do ISEB e do núcleo de intérpretes da formação brasileira em sua tese não impediu "o educador de imprimir às análises as marcas de suas próprias reflexões e experiências", como a "vivência das condições de subdesenvolvimento do Nordeste, que o levaria a acentuar, em sua compreensão da 'atualidade 
brasileira' a presença das características da vida social agrária e do estilo de vida senhorial de dominação".

Ainda no plano das grandes sínteses sobre a formação do Brasil, os temas assinalados/anotados por Freire nas páginas de A cultura brasileira, de Fernando de Azevedo, revelam a apropriação da tese da falta, da não experiência, de atrofia da participação em detrimento do "mandonismo". A falta e a ausência (como experiências que não aconteceram, que foram obliteradas) contrastam a ocupação territorial brasileira com o sentido da colonização estadunidense, tal como Fernando de Azevedo coloca em perspectiva o modelo português e o modelo estadunidense. Os pontos assinalados por Freire nas páginas de $A$ cultura brasileira realçam o encaminhamento para a grande propriedade, na colonização portuguesa do Brasil, raiz do poder dos proprietários para além de seus domínios territoriais, enquanto que o modelo americano seguiu o caminho oposto:

O desenvolvimento das cidades é um dos mais importantes fatores que contribuem para a produção do fenômeno da cultura - 30 - A educação meramente como força meramente transmissora de cultura - 35 - Considerações importantes sobre a posição da América Latina e a necessidade de sua integração para autenticar-se - 48/49 - O fator geográfico explicando a dispersão populacional - 55 - Populações de Portugal ao tempo de descoberta - 58 - A autorização da grande propriedade e o individualismo brasileiro - 88 - A expansão territorial americana, ordenada e contínua, acompanhada de desenvolvimento econômico e a massa, desordenada e sem esse desenvolvimento - 88 - $\mathrm{O}$ traço escravo e a monocultura latifundiária continuaram na economia do café - 91 - A estreita política da metrópole estrangulando, entre outros fatores, o desenvolvimento da manufatura - 94.

A ausência das experiências de participação também é explicada conforme a tese da falta, cujos efeitos são permanências que tencionam com os ímpetos de participação na fase de trânsito. Nas suas anotações nas páginas de $A$ cultura brasileira, Freire pré-elaborou parte de um tópico de destaque em sua tese, a inexperiência democrática, e que nessa passagem está orientado pelo sentido de falta, de exiguidade de participação popular devido ao tipo de colonização do Brasil: 
[Anotação de Paulo Freire no livro] A inexperiência política das massas brasileiras - 167/168 - O nosso preconceito contra o trabalho - 168 [Transcrição do livro por Freire] "Mas tanto o império, que não pode subtrair-se às tenazes do bloqueio liberal como a República Federativa que Ihe sucedeu, eram super estruturas decalcadas em modelos teóricos por uma elite sem povo e sem organização da opinião pública, minadas pelas lutas partidárias, políticas e militares e emperradas pela burocracia de [ilegível], que tornaria laborioso o seu processo de adaptação às formas e às condições da vida social." [Anotação de Paulo Freire no livro] Na página 172, transcrever o trecho que começa com a palavra mas e termina com nativos. Transcrever na página 178 das palavras: as grandes [ilegível] até preventivo. Transcrever da página 175 a partir das palavras que as ideias até na página 176 a palavra nacional. Transcrever na página 185 de certamente até nação irracional e do místico, de que deriva uma ênfase do emocional e do imaginoso nos atos da inteligência. O compromisso de nossas ações em todos os planos derivados dessa nota. Considerações muito boas a esse respeito - 195/196/197 Para isso, esse problema se acha vinculado estreitamente à nossa inexperiência democrática, de que resulta 0 comportamento geral brasileiro novamente na assistencialização. Faltou-nos, realmente, o diálogo. O que não aconteceu nos Estados Unidos. Transcrever na página 203 desde essa instabilidade até distinção. Transcrever da página 206 de mas até na 207 sertão - o individualismo, o forte [ilegível] e a falta de cooperação no brasileiro - 207

A elaboração da ideia de inexperiência democrática, na tese de Freire, absorveu a interpretação da história de Fernando de Azevedo em combinação com os outros nomes da bibliografia dos analistas da formação do Brasil. As marginalias nas páginas de $A$ cultura brasileira indicam que Freire desejava esclarecer como as estruturas de poder, desde a sua gênese durante a colonização, se perpetuaram geração após geração, não somente do ponto de vista material como também enquanto mentalidade que conformou a psicologia do homem nacional. Por isso, o Fernando de Azevedo, autor de $A$ cultura brasileira é uma escolha de Paulo Freire:

Centralismo, verbalismo, anti-dialogação, autoritarismo, "assistencialização" são manifestações de nossa inexperiência democrática, conformada em atitudes ou disposições mentais, constituindo, tudo isso, um dos dados de nossa atualidade. Dos mais fortes. Dos mais presentes. Dos mais perturbadores do 
ritmo de nossa democratização, outro dado de nossa atualidade, situado mais no hoje dessa atualidade. (FREIRE, 1959, p. 11)

Do ponto de vista material, a industrialização ensejava mudanças profundas no Brasil, a exemplo da urbanização, do princípio de deslocamento do eixo da economia de agrária para industrial, da criação de um mercado consumidor e de trabalho, o que condizia com a conjuntura apreendida por Freire no final dos anos 1950. De outra parte, o lado educador de Freire orientava o analista da realidade brasileira de início da segunda metade do século. Numa sociedade de profundas raízes coloniais como o Brasil, os limites para o aprofundamento das mudanças provocadas pela industrialização logo seriam alcançados se a disputa contra o país arcaico não enfrentasse a dimensão mental do atraso, ou, na expressão de Freire (1959, p. 67) o "clima culturológico". A renovação do agir educativo (expressão usada por Freire) seria fundamental para colocar a educação escolar em posição de organicidade em relação à fase de trânsito.

\section{CONSIDERAÇÕES FINAIS}

Paulo Freire se mostrou um bom colecionar de repertórios teóricos e bibliográficos em sua tese a fim de definir o problema (a antinomia fundamental da atualidade), o alcance e a profundidade do exame dessa questão e um programa de reformas cuja plataforma de lançamento seria a educação escolar. Para essa empreitada, Freire recorreu a intelectuais europeus e brasileiros, a expressões do existencialismo cristão, da psicologia social, do pragmatismo, da historiografia e da sociologia brasileiras da primeira metade do século XX, do escolanovismo brasileiro e de expoentes do nacional desenvolvimentismo. Esse elenco de referências, por sua vez, fundamenta núcleos temáticos da tese em alguns casos e, em outros, sustenta discussões transversais que tem lugar em mais de um capítulo e contribuem para o desenvolvimento de análises como a da ausência de experiências de participação na formação histórica brasileira. 
Em comparação com os livros que viriam a lume após 1964, Educação e atualidade brasileira é explícito quanto a sua natureza de tese acadêmica porque mostra um autor mais contido, cauteloso e procurando apoiar sua análise em argumentos de autoridade, embora o estilo de pensar dialogado convertido em texto, comunicado ao leitor, dando maleabilidade às palavras ao ponto de forjar neologismos (mutismo, quietismo, assistencialização, bacharelismo, formalismo) já se apresente nesse trabalho. Apesar do tom monográfico, Paulo Freire ensaia navegar um pouco mais longe da costa em Educação e atualidade brasileira ao procurar um espaço entre três eixos intelectuais fortes do debate público brasileiro dos anos 1950. Para se colocar, Freire tinha a vivência de educador, a consciência dos contrastes da vida social do nordeste ao lado da postura intelectualmente interessada e disciplinada numa cidade como o Recife, rica em vida intelectual, dotada de livrarias, o que fazia o educador dispor do suprimento de livros que abasteceram sua biblioteca (FREIRE, 2017). No Recife o Centro Brasileiro de Pesquisas Educacionais - umas das muitas realizações capitaneadas por Anísio Teixeira - fez instalar uma de suas filiais, o Centro Regional de Pesquisas Educacionais, sob a orientação de Gilberto Freyre. Paulo Freire frequentou as conferências e cursos realizados pelo CRPE-Recife, assistiu Anísio Teixeira em conferência e incorporou os documentos e análises do centro e do escolanovista à sua tese. Por essas e outras vias, como a do estudo sistemático, Freire preparou as linhas que seguiria na escrita de Educação e atualidade brasileira. As notas que reproduzimos neste artigo e os excertos da tese com os quais foram cotejadas indicam que o entendimento que o leitor Paulo Freire extraía e registrava nas margens e pés de página orientaram a elaboração de temas como o problema da formação do Brasil enquanto colônia, a mentalidade democrática, bem como deixam antever um critério de ordenamento e escolha de bibliografia que pudesse introduzir sua contribuição a um debate sobre projetos de país em disputa na década de 1950. 


\section{REFERÊNCIAS}

BEISIEGEL, Celso de Rui. Política e educação popular: a teoria e prática de Paulo Freire no Brasil. São Paulo: Ática, 1982.

FONSECA, Sérgio César da. Paulo Freire e Anísio Teixeira: convergências e divergências. Jundiaí: Paco, 2011.

FREIRE, Ana Maria Araújo. Paulo Freire: uma história de vida. 2. ed. Rio de Janeiro: Paz e Terra, 2017.

FREIRE, Paulo Reglus Neves. Educação e atualidade brasileira. Recife: Escola de Belas Artes de Pernambuco, 1959.

GADOTTI, Moacir. A voz do biógrafo brasileiro: a prática à altura do sonho. In: GADOTTI, Moacir (org.). Paulo Freire: uma biobibliografia. São Paulo: Cortez/IPF; Brasília: UNESCO, 1996.

GERHARDT, Heinz-Peter. Uma voz européia: arqueologia de um pensamento. In: GADOTTI, Moacir (org.). Paulo Freire: uma biobibliografia. São Paulo: Cortez/IPF; Brasília: UNESCO, 1996.

GREEN, Elliott D. What are the most-cited publications in the social sciences (according to Google Scholar)?. London School of Economics and Political Science, Londres, 12 mar. 2016. Acesso em: 25 mar. 2020. Disponível em: https://blogs.Ise.ac.uk/impactofsocialsciences/2016/05/12/what-are-the-mostcited-publications-in-the-social-sciences-according-to-google-scholar/

HADDAD, Sérgio. O educador: um perfil de Paulo Freire. São Paulo: Todavia, 2019.

KOHAN, Walter. Paulo Freire mais do que nunca. Uma biografia filosófica. Belo Horizonte: Vestígio, 2019.

PAIVA, Vanilda Pereira. Paulo Freire e o nacionalismo-desenvolvimentista. Rio de Janeiro: Civilização Brasileira, 1980.

ROMÃO, José Eustáquio. Paulo Freire e o Pacto Populista. In: FREIRE, Paulo Reglus Neves. Educação e Atualidade Brasileira. São Paulo: Cortez, 2001.

SOUZA, Ana Inês. Educação e atualidade brasileira: a emersão do povo na história. In: SOUZA, Ana Inês; SCHNORR, Gisele Moura; SCHWENDLER, Sônia Fátima; BERTOLINI, Targélia de Souza Albuquerque; ZANETTI, Maria Aparecida. Paulo Freire: vida e obra. São Paulo: Expressão Popular, 2001.

SOUZA, Ana Inês; SCHNORR, Gisele Moura; SCHWENDLER, Sônia Fátima; BERTOLINI, Targélia de Souza Albuquerque; ZANETTI, Maria Aparecida. Paulo Freire: vida e obra. São Paulo: Expressão Popular, 2001. 
STRECK, Danilo R.; REDIN, E.; ZITKOSKI, J. J. (Orgs.). Dicionário Paulo Freire. 2. ed. rev. e ampl. Belo Horizonte: Autêntica Editora, 2010.

TEIXEIRA, Maria Cecília Sanchez. Discurso pedagógico, mito e ideologia: o imaginário de Paulo Freire e Anísio Teixeira. Rio de Janeiro: Quartet, 2000.

Recebido em: 10/11/2020

Aprovado em: 01/12/2020 